\title{
Comparative study on economic security of enterprises depending on implemented business activities quantity
}

\author{
Tatyana Shkarina ${ }^{1, *}$, Olga Chudnova $^{1}$, and Olga Mokhova $^{1}$ \\ ${ }^{1}$ Far Eastern Federal University (FEFU), Engineering school, 690018 Russky Island, Russia
}

\begin{abstract}
The results of a comparative study on economic security of enterprises depending on the quantity of business activities are published in the article. The sampling for analysis was conducted based on statistic data of Primorsky Region of the Russian Federation. The control points are the years of the most thorough data collection on the business activities of one-field and diversified enterprises: 2005, 2009, 2013, 2015.
\end{abstract}

Each enterprise is a dynamically developing economic system. Economic system is characterized with structural diversity of elements and connections both within the system itself and with external parties. In order for this system to function productively, it is necessary to maintain its economic security. Security, in this case, is defined as consistency of system pathology or continuance of its status sequences over time during its metamorphosis.

Economic security of enterprise, much alike commercial activity itself, - is a complex concept; the first characterizes business activities with regard to external influences and can be considered secure if under equal external and internal shifts it is more robust to changes comparing to original status. This said, economic condition of an enterprise may vary from extremely volatile, under which it is borderline bankrupt, to relatively secure.

Security - is an external manifestation of object structure. In order to increase its stability against various factors, primarily, it is necessary to improve the object itself.

Security of business object is an aggregate of independent, singular and private balances. It is higher when the aggregate of stable balances of business object exceeds the quantity of unstable ones.

The goal of given study - is determination of the most economically secure type of enterprise when organizing one-field or diversified production.

One-field enterprises - are the enterprises that produce one type of goods, have one type of sphere of activity, one specialization.

Diversified enterprises - "are enterprises with profile activity concentrated in various businesses, operating in various markets, however, administration and functional supply are most frequently concentrated on one platform".
Aggregation of study sampling was determined based on development of one-field and diversified enterprises conducting business in Primorsky Region.

Timeliness of the study is defined with economic development of Primorsky Region due to creation of zone of porto-franco free port Vladivostok, which has obtained its status since October 12, 2015. The main goal of creating such zone is formation of secure regional development, which is impossible without achievement of economic security of separate enterprises. Capital investments in development of crossborder trade, transport infrastructure and network of logistic centers with specific storage conditions will allow enterprises to establish comfortable external connections. However, achievement of internal security has the role that is not less important and requires clear understanding which business has the highest economic security: the one that focuses on one type of activities or the one that has several types of activities [1-3].

During the conduct of research activity profile of enterprise was not considered. Division of enterprises was based on the only criteria - whether the enterprise has more than one profile. The volumes of statistic data was taken from the official reports of Regional Bureau of Statistics. The control points are the years of the most thorough data collection on business activities of onefield and diversified enterprises: 2005, 2009, 2013, 2015. The aggregates of the control points formed based on enterprise activity and quantity of types of implemented activities.

The research method is the comparative analysis method.

For the purposes of research, 2800 enterprises of medium and large business, which implement activities in Primorsky Region of the Russian Federation, were selected [4].

Considered data is represented in statistic tables by separate aggregations (Table 1 - Aggregation of onefield enterprises, Table 2 - Aggregation of diversified

\footnotetext{
Corresponding author: shkarina.tyu@dvfu.ru
} 
enterprises). The aggregations of one-field enterprises are labeled in accordance with years: 2005-a, 2009-в, 2013-c 2015-d. The aggregations of diversified enterprises are labeled in accordance with years: $2005-x$, 2009-y, 2013-z, 2015-g.

The type of development dynamics of enterprises is labeled as follows: 0 - enterprise did not conduct activities during the researched timeframe; 1 - enterprise operated as one-field organization during the researched period; $\mathrm{M}$ - enterprises functioned as diversified enterprises during the researched timeframe [4-8].

Table 1. Aggregation of one-field enterprises.

\begin{tabular}{|c|c|c|c|c|c|c|c|c|}
\hline $\begin{array}{c}\text { Type } \\
\text { of } \\
\text { develo } \\
\text { pment }\end{array}$ & \multicolumn{2}{|c|}{2005} & \multicolumn{2}{|c|}{2009} & \multicolumn{2}{|c|}{2013} & \multicolumn{2}{|c|}{2015} \\
\hline $1-1-1-0$ & \multirow{3}{*}{ a1 } & 151 & \multirow{3}{*}{ b1 } & 151 & \multirow{3}{*}{$\mathrm{c} 1$} & 151 & \multirow{3}{*}{ D1 } & 0 \\
\hline $\begin{array}{c}1-1-1- \\
M\end{array}$ & & 151 & & 151 & & 151 & & 101 \\
\hline $1-1-1-1$ & & 151 & & 151 & & 151 & & 50 \\
\hline $1-0-0-0$ & \multirow{3}{*}{$\mathrm{a} 2$} & 345 & \multirow{3}{*}{$\mathrm{b} 2$} & 0 & \multirow{3}{*}{ c2 } & 0 & \multirow{3}{*}{ D2 } & 0 \\
\hline $1-0-0-1$ & & 345 & & 0 & & 0 & & 0 \\
\hline $\begin{array}{c}1-0-0- \\
M\end{array}$ & & 345 & & 0 & & 0 & & 0 \\
\hline $1-1-0-0$ & \multirow{3}{*}{ a3 } & 100 & \multirow{3}{*}{ b3 } & 100 & \multirow{3}{*}{ c3 } & 0 & \multirow{3}{*}{ D3 } & 0 \\
\hline $1-1-0-1$ & & 100 & & 100 & & 0 & & 0 \\
\hline $\begin{array}{c}1-1-0- \\
M\end{array}$ & & 100 & & 100 & & 0 & & \\
\hline \multicolumn{9}{|c|}{$\ldots$} \\
\hline $\begin{array}{c}\text { M-0-1- } \\
0 \\
\end{array}$ & \multirow{3}{*}{ a19 } & 0 & \multirow{3}{*}{ b19 } & 0 & \multirow{3}{*}{ c19 } & 2 & \multirow{3}{*}{$\begin{array}{c}\text { D1 } \\
9\end{array}$} & 0 \\
\hline $\begin{array}{c}\text { M-0-1- } \\
1 \\
\end{array}$ & & 0 & & 0 & & 2 & & 2 \\
\hline $\begin{array}{c}\text { M-0-1- } \\
\text { M }\end{array}$ & & 0 & & 0 & & 2 & & 0 \\
\hline $\begin{array}{c}\text { Total } \\
\text { of } \\
\text { enterpr } \\
\text { ises in } \\
\text { aggreg } \\
\text { ate }\end{array}$ & \multicolumn{2}{|c|}{702} & \multicolumn{2}{|c|}{811} & \multicolumn{2}{|c|}{1014} & \multicolumn{2}{|c|}{1116} \\
\hline
\end{tabular}

Evolution of aggregate changes is shown in Figures 2 and Figure 3. In this case evolution is defined as "expansion" of researched organizations, and, in particular, determination of frequencies of creation, reorganization and saving [9].

Looking at the obtained analysis data on one-field and diversified organizations, it is notable that this is matrix presentation of planar net graphs, table 1 and table 2 .

Eye charts are built for the analysis of matrix structure of planar net graphs evolution; as a result, the types of graphs for all researched organizations are the following (Figures 1a and Figure 1b) [10-11].
Table 2. Aggregation of diversified enterprises.

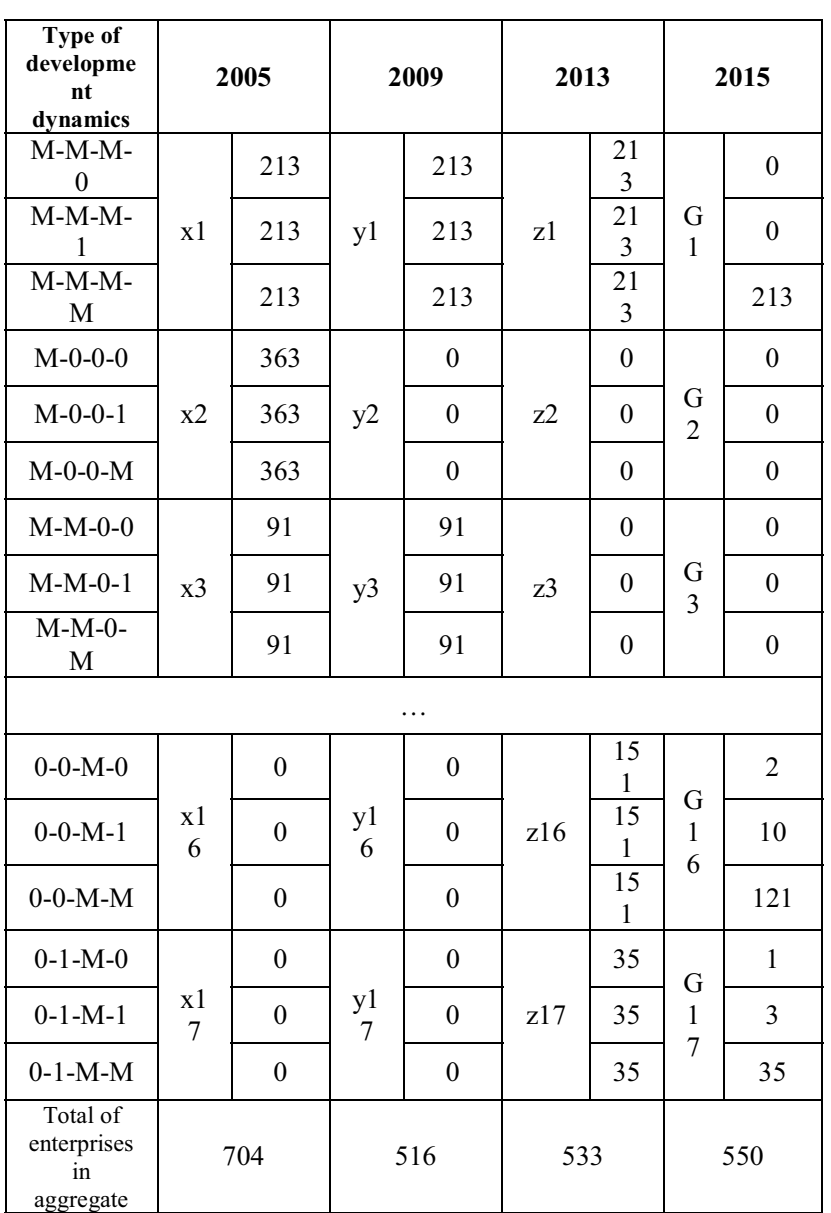

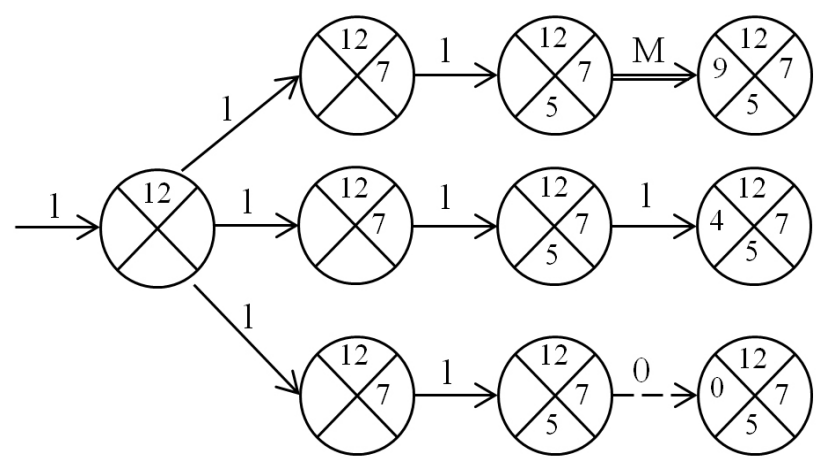

a)

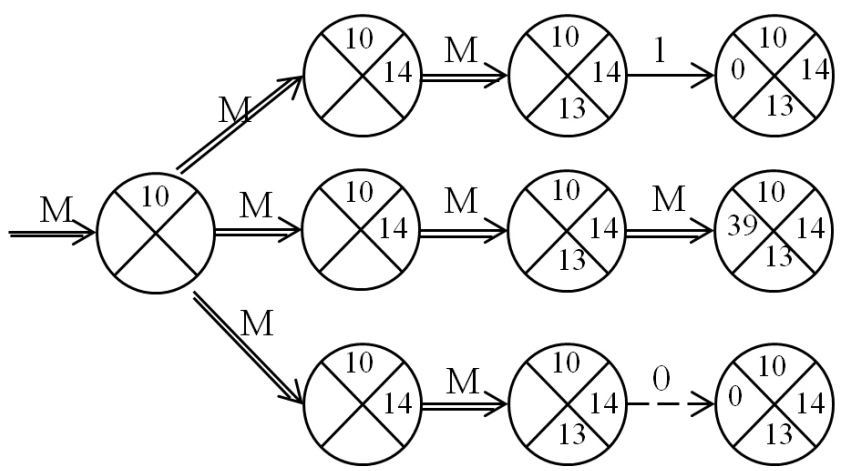

b)

Fig. 1. Planar net graphs of one-field (a) and diversified (b) organizations. 


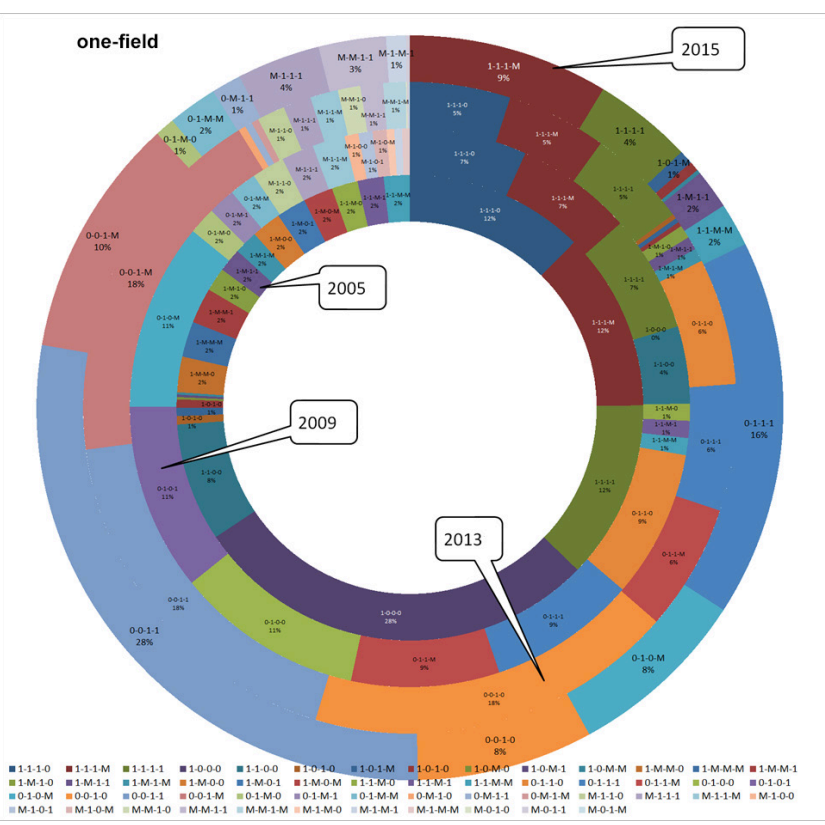

Fig. 2. Evolution of aggregate changes in one-field organizations.

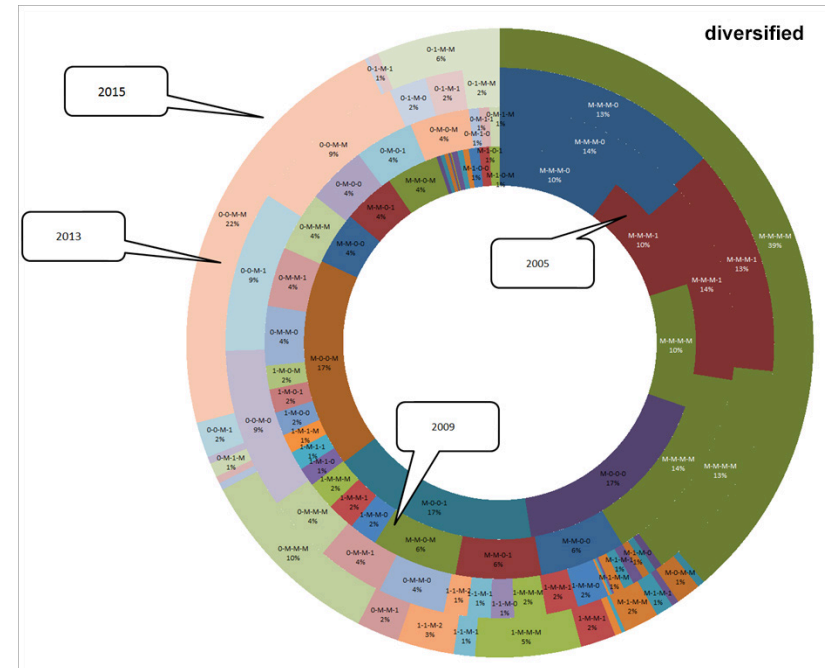

Fig. 3. Evolution of aggregate changes in diversified organizations.

Peculiarity of presented model is the presence of two types of graphs: "organization profile" $(0,2$ and $\mathrm{M})$ and segment. Based on graph structure evolution chains of development of researched organizations build up effortlessly, Figures 4 and 5.

We are interested in organizations with highest security. Security is defined as the ability to administrate and maintain the set, yet adjustable operation mode with particular precision and ability to recover it in case of malfunction. For the purposes of security analysis, eye charts were built based on changes in aggregates of organization profiles [12-14].

Analysis of changes in aggregate of one-field and diversified organizations gives and opportunity to form evolution chains of one-field organizations. As a result of analysis, evolution chains were formed as follows, Figures 4 and 5:
1) Organizations that are capable to sustain the set adjustable operation mode with specific precision;

2) Organizations that are capable to regulate the set operation mode with specific precision;

3) Organizations that are capable to recover the set adjustable operation mode with specific precision.

\begin{tabular}{|c|c|c|c|c|c|}
\hline \multicolumn{2}{|c|}{ Sustainability } & \multicolumn{2}{|c|}{ Adjustability } & \multicolumn{2}{|c|}{ Recovery } \\
\hline $1-1-1-1$ & $12 \rightarrow 7 \rightarrow 5 \rightarrow 4$ & 1-1-1-M & $12 \rightarrow 7 \rightarrow 5 \rightarrow 9$ & $0-1-0-\mathrm{M}$ & $0 \rightarrow 11 \rightarrow 0 \rightarrow 8$ \\
\hline $0-1-1-1$ & $0 \rightarrow 9 \rightarrow 6 \rightarrow 16$ & 1-1-M-M & $2 \rightarrow 1 \rightarrow 1 \rightarrow 2$ & $0-0-1-\mathrm{M}$ & $0 \rightarrow 0 \rightarrow 18 \rightarrow 10$ \\
\hline $0-0-1-1$ & $0 \rightarrow 0 \rightarrow 18 \rightarrow 28$ & 1-M-1-1 & $2 \rightarrow 1 \rightarrow 1 \rightarrow 2$ & 0-1-M-M & $0 \rightarrow 6 \rightarrow 9 \rightarrow 2$ \\
\hline & & 1-1-M-1 & $2 \rightarrow 1 \rightarrow 1 \rightarrow 2$ & 0-1-M-1 & $0 \rightarrow 2 \rightarrow 1 \rightarrow 1$ \\
\hline & & & & 1-M-1-1 & $2 \rightarrow 1 \rightarrow 1 \rightarrow 2$ \\
\hline
\end{tabular}

Fig. 4. Evolution chains of development of one-field organizations

\begin{tabular}{l|l|l|l|l|l}
\multicolumn{2}{c|}{ Sustainability } & \multicolumn{2}{c|}{ Adjustability } & \multicolumn{2}{c}{ Recovery } \\
\hline M-M-M-M & $10 \rightarrow 14 \rightarrow 13 \rightarrow 39$ & M-M-M-1 & $10 \rightarrow 14 \rightarrow 13 \rightarrow 1$ & $0-1-M-M$ & $0 \rightarrow 1 \rightarrow 2 \rightarrow 6$ \\
$0-M-M-M$ & $0 \rightarrow 4 \rightarrow 4 \rightarrow 10$ & M-1-M-1 & $1 \rightarrow 0 \rightarrow 1 \rightarrow 1$ & M-M-0-M & $1 \rightarrow 0 \rightarrow 1 \rightarrow 1$ \\
$0-0-M-M$ & $0 \rightarrow 0 \rightarrow 9 \rightarrow 22$ & M-1-M-M & $1 \rightarrow 1 \rightarrow 1 \rightarrow 2$ & M-0-0-M & $17 \rightarrow 0 \rightarrow 0 \rightarrow 0$ \\
& & & & M-0-M-1 & $2 \rightarrow 0 \rightarrow 1 \rightarrow 1$ \\
& & & & M-0-1-M & $1 \rightarrow 0 \rightarrow 0 \rightarrow 0$ \\
& & & & $0-M-1-M$ & $1 \rightarrow 1 \rightarrow 2 \rightarrow 1$
\end{tabular}

Fig. 5. Evolution chains of development of diversified organizations.

For the considered organizations, it is necessary to sustain maximum feasibility for as long as possible, meaning to stay in market for a prolonged period of time, and this is nothing less then the concept of critical path in the theory of net graphs [15-16]. Surely, lately this given concept is mainly used for evaluation of duration of implementation of innovative projects and optimization of deadlines. Nevertheless, in our case it is necessary to remain in operating mode - "in project". Thus, we need to evaluate the attained evolutional chains-branches of the graph [17-20].

Each organization profile (atop the graph) is associated with number $T_{i}$, called the early occurrence of event $i$. It is the minimum value of implementation filled in segment (weight) of event $i$ (process with a start point in this extremum must begin not earlier the moment $T_{i}$ ) [21-25]:

$$
T=\mid \begin{gathered}
T_{0} \\
\max \left(T_{i}+T_{j}\right), j-\text { value of filled in segment (weight) } \\
\{i, j\}
\end{gathered}
$$

Calculations of $\mathrm{Tj}$ - critical path of evolution chainsgraphs in case of «1-1-1-1» are the following:

$$
\left.\begin{array}{c}
T_{0} \\
T_{l}=T_{0}+" 1 "=0+12=12 \\
T_{l-l}=T_{1}+" 1 "=12+7=19 \\
T_{l-l-l}=T_{l-l}+1 "=19+5=24 \\
T_{l-l-l-l}=T_{l-l-l}+" 1 "=24+4=28
\end{array}\right\} \Rightarrow 28
$$

Thus, upon calculations of all chains-graphs we attain the following (Figures $6 a$ and $b$ ). 
The advantage of such analysis is that it allows determining interaction effect and evaluating security of considered organizations.

The analysis shows that sustainability and adjustability is higher in diversified organizations, whereas recovery indicators are the highest in one-field organizations.

\begin{tabular}{|c|c|c|c|c|c|c|c|c|c|}
\hline \multirow{3}{*}{$\begin{array}{l}\text { Organiza } \\
\text { tions } \\
\text { One-field }\end{array}$} & \multicolumn{6}{|c|}{ Critical paths of evolutional chains-graphs } & \multicolumn{3}{|c|}{ max rang } \\
\hline & \multicolumn{2}{|l|}{ 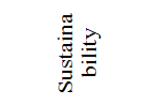 } & \multicolumn{2}{|l|}{$\frac{3}{3}$} & \multicolumn{2}{|l|}{ 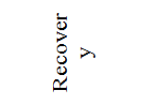 } & 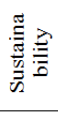 & 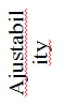 & 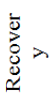 \\
\hline & $\begin{array}{l}1-1-1-1 \\
0-1-1-1 \\
0-0-1-1\end{array}$ & $\begin{array}{l}28 \\
31 \\
46\end{array}$ & $\begin{array}{l}1-1-1-\mathrm{M} \\
1-1-\mathrm{M}-\mathrm{M} \\
1-\mathrm{M}-1-1 \\
1-1-\mathrm{M}-1\end{array}$ & $\begin{array}{c}33 \\
5 \\
5 \\
5\end{array}$ & $\begin{array}{l}0-1-0-\mathrm{M} \\
0-0-1-\mathrm{M} \\
0-1-\mathrm{M}-\mathrm{M} \\
0-1-\mathrm{M}-1 \\
1-\mathrm{M}-1-1\end{array}$ & $\begin{array}{l}19 \\
28 \\
17 \\
4 \\
6 \\
\end{array}$ & 46 & 33 & 28 \\
\hline Diversified & $\begin{array}{l}\text { M-M-M-M } \\
0-\mathrm{M}-\mathrm{M}-\mathrm{M} \\
0-0-\mathrm{M}-\mathrm{M}\end{array}$ & $\begin{array}{l}76 \\
18 \\
31\end{array}$ & $\begin{array}{l}\text { M-M-M-1 } \\
\text { M-1-M-1 } \\
\text { M-1-M-M }\end{array}$ & $\begin{array}{l}51 \\
3 \\
5\end{array}$ & $\begin{array}{l}0-1-M-M \\
\text { M-M-0-M } \\
\text { M-0-0-M } \\
\text { M-0-M-1 } \\
\text { M-0-1-M } \\
0-\mathrm{M}-1-\mathrm{M}\end{array}$ & $\begin{array}{l}9 \\
3 \\
17 \\
4 \\
1 \\
5\end{array}$ & 76 & 51 & 17 \\
\hline
\end{tabular}

a)

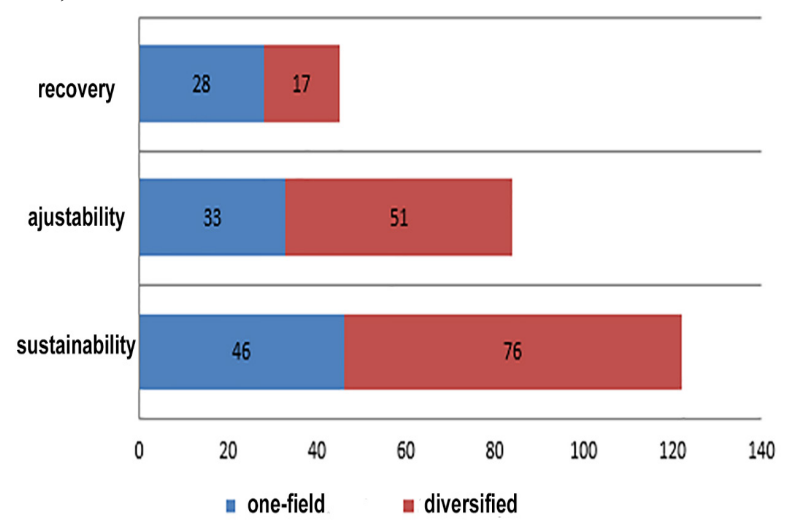

b)

Fig. 6. Max rang of chains-graphs.

These results may be determined by instabilities in requirements for each type of activity under conditions of constantly changing legislature on one hand and opportunities for formation of more secure business at the expense of diversification in accordance with changing conditions on the other.

\section{References}

1. About the free port of Vladivostok: the federal law of the Russian Federation of 2015. http://www.consultant.ru/document/cons_doc_LAW _182596/

2. About the territories of the advancing social and economic development in the Russian Federation: the federal law of the Russian Federation of 2014, no. 473-FL, Russian newspaper, 6571 (2014)

3. The territories of the advancing social and economic development. http://minvostokrazvitia.ru/

4. The territorial body of the Federal State Statistics Service for Primorsky Krai. http://primstat.gks.ru/
5. T.Yu. Shkarina, O.A. Chudnova, Quality Management (University textbook Far Eastern Federal District, 2015)

6. E.V. Yarotskaya, Scientific-methodical electronic journal "Koncept", 20, 4391 (2014). http://ekoncept.ru/2014/ 55143.htm

7. T.Yu. Shkarina, S.A. Gruzdeva, Economics and administration: scientific journal, 1, 102 (2010)

8. ISO 9000:2015 Quality management systems, Fundamentals and vocabular

9. Academic Dictionaries and Encyclopedias. http://dic.academic.ru

10. L.R. Batukova, Journal of Vestnik of SibGAU, 2(15), $110 \quad$ (2007). http://elibrary.ru/ contents.asp? issueid $=456573$

11. L.R. Batukova, G.S. Mikhalev, Journal of Vestnik of SibGAU, 2(35), 212 (2011)

12. K. Berg, Theory of graphs and its applications (1962)

13. R. Diestel, Graph Theory, Electronic Edition (Springer-Verlag, NY, 2005)

14. A.S. Geida, SPIIRAS Proceedings, 2(17), 234 (2011)

15. V.V. Yudin, O.A. Chudnova, Bulletin Of The Russian Academy Of Sciences: Physics, 10, 1405 (2001)

16. V.V. Yudin, O.A. Chudnova, Journal of Crystallography Reports, 47(2), 189 (2002)

17. V.L. Sharstnyov, E.Yu. Vardomatskaya, Management of economic systems, 05 (2006)

18. A.V. Zemtsov, Methodical journal: Bank crediting, 6 (2008).http://www.reglament.net/bank/credit/2008_6 .htm

19. GOST R 56716-2015 Project management. Project network techniques. Descriptionsandconcepts. http://docs.cntd.ru/ document/1200127270

20. GOST R 21500-2014 Guidance on project management.http://docs.cntd.ru/document/12001180 20

21. E. Börger, R. Staerk, Abstract State Machines: A Method for High - Level System Design and Analysis (Springer - Verlag, Berlin, 2003)

22. I. G. Abramova, Project management based on network models (Samar. State. Aerospace. Un-t, Comp, 2007)

23. V.N. Burkov, D.A. Novikov, Elements of graph theory. http://www.mtas.ru/about/

24. M.A. Korotkov, Methods of network planning (2003)

25. R.V. Dopira, R.Yu. Kordyukov, Product and system program, 2(106), 22 (2014) 